\title{
INFLUENCE OF SURFACE TENSION OF WATER ON DROPLET SIZE PRODUCED BY FLAT JET NOZZLES
}

\author{
Stanisław PARAFINIUK ${ }^{1}$, Marek MILANOWSKI ${ }^{1}$, Alaa SUBR ${ }^{2}$, \\ Anna KRAWCZUK ${ }^{1}$ \\ ${ }^{1}$ Department of Machinery Exploitation and Management of Production Processes, University of Life \\ Sciences in Lublin, POLAND \\ ${ }^{2}$ Department of Agricultural Machines and Equipment, College of Agriculture, University of Baghdad, \\ IRAQ \\ E-mail of corresponding author: stanislaw.parafiniuki@ up.lublin.pl
}

Keywords:, adjuvant, droplet size, Volume Median Diameter, surface tension, flat fan nozzles.

\begin{abstract}
The aim of the study was to check if the quality of water which was taken from different sources (used for plant protection treatments) influences the droplet size generated by agricultural nozzles. The experiment was done in the laboratory of the University of Life Sciences in Lublin (UP Lublin), and water from 3 different sources was used, demineralized water was used as reference water. There were two treatements of adjuvant (Superam 10AL): with and without adjuvant. The water quality was assessed on the basis of the change of surface tension. The surface tension was measured with a drop Shape Analizer DSA30 device. The Flat Fan, one of the agricultural nozzles widely used by farmers, was used in the study. The measurement was done with spraying pressure of the following values: 2 bar, 3 bar and 4 bar with three repetitions. The droplet size was measured with a laser diffractometer HELOS/R - Sympatec. The results show that using the adjuvant changed the surface tension for all the types of the water sources. However, this change was higher for the water from the farm well (source B) and the tap water from UP Lublin building (source C). This change in the surface tension alters in turn the drops size (Volume Median Diameter) depending on the average results of the spray patteren, but only when using 3-bar pressure.
\end{abstract}

\section{INTRODUCTION}

According to the EU Directive 2009/128 /EC on the sustainable use of pesticides, there is a need to reduce the impact of pesticides on the environment. Integrated protection involves the use of all available methods and ways to ensure safe and effective crop growth, and ensuring protection of the environment and human health, providing positive economic effects as well. Using the principle of sustainable use of pesticides should draw attention to the techniques used in the treatment of plant protection. The important issue here is the appropriate fit of the spraying techniques, taking into account the degree of plants coverage and the size of droplets produced by the agricultural sprayer. Therefore, in agricultural practice a standard ASAE S572.1 (2009) is the most often used standard for determining the droplet size produced by agricultural nozzles.

Flat fan nozzles and their operating parameters defining a plurality of standards and regulations have been extensively studied. Their technical condition and performance have a very big impact on the degree of coverage on the plants and this results in biological and economical effectiveness of the treatment as well as human and environment safety (Huyghebaert, 2015).

The droplet size has an important effect on the pesticide application process. For example, small size droplets have a tendency to drift and cause environmental problem. Subr et al. (2015) found that reducing the spraying pressure (from 3 to 2 and then to 1 bar) results in smaller drops size (VMD) in the center and edges of the spray pattern.

In agriculture, different types of water are used for crop protection activities depending on the location of the farm, and each of them has a different surface tension. Surface tension has influence on the quality of the produced spray droplets, which effects in turn the degree of coverage on the plants surfaces. Therefore, the most appropriate droplet 
size for the spraying, and the dose of the adjuvant should be included on the label of a plant protection product (Czaczyk, 2014).

Decresing the surface tension of pure spray causes a decrease in the droplet size for three types of nozzles tested by Butler Ellis et al. (2001). However, the degree of this decrease which depends on the nozzle type is less than expected by spray formation theories. Massinon et al. (2017) observed an increase in the quantity of drops reaching a pre-wetted surface of bean and avocado as the surface tension of the spray decreased.

Butler Ellis et al. (1997), confirmed that the quality of the spray produced by flat-fan nozzles is influenced significantly by the liquid properties, the last one could be changed by adding the adjuvants. For example and according to their research, using the adjuvants influenced the variations of droplet size significantly, and also affected the spray fan thickness.

The aim of the study was to verify and determine how water taken from a different sources, with variable surface tension and with or without the adjuvant has an impact or changes the droplet size produced from agricultural nozzles.

\section{MATERIALS AND METHODS}

The water used in the test came from four different sources :

A: demineralized water obtained from the laboratory of the UP Lublin; B: farm well located in the village of Sosnówka; C: tap water from UP Lublin building; D: tap water from a farm located in the municipality of Sosnówka.

Surface tension was measured by using the device DSA30 Kruss by hanging drop. In this method, based on the obtained image and the drop shape analysis evaluates the surface tension. Before taking measurements to the software that controls the operation of device introduced the necessary data about the diameter of a needle dispensing measured drops $(1.828 \mathrm{~mm})$ and a density of analyzed samples $(0.998 \mathrm{~g} / \mathrm{cm} 3)$. Then, each sample was taken after 10 measurements of the surface tension of injecting drops of a certain volume following the recommendations of the manufacturer (User Manual V1.92-03, 2004). A drop should be large enough to allow the weight to keep the needle tip and measurement of the value of surface tension. For water without adjuvant there were dispensed droplets with a volume of $28 \mathrm{ml}$ while for the water to $100 \%$ the recommended dose of adjuvant droplet size allowing for measurement was $14 \mathrm{ml}$. Dispensing drops was carried out by the program control device.

Three TeeJet XR 110/03 nozzles were used to test the size of droplets. Before initiating the test, the flow rate of the nozzles was checked to be sure if it is the same like the nominal flow rate provided by the producer. The measurements of droplet size were done during the flow of the spray and with three repetitions for every position of the spray pattern. The used working pressure was 2, 3, 4 bar and it was gained from air pressurized water tank. The start and stop of the spray was controlled with a solenoid valve, and the position of the nozzle regarding the sampling area was controlled by an electro-mechanical positioning system and with the help of computer software.

The measurement of the droplet size was done by using laser diffractometer HELOS KR with a measuring range of 1 to 3500 microns. The nozzle was positioned in the axis of the laser light and moved every $20 \mathrm{~cm}$ intervals in both directions. The distance between the nozzle tip and the laser light was $50 \mathrm{~cm}$. 


\section{RESULTS}

The addition of adjuvant contributed to reduction of the surface tension of water from each source. However, it should be noted, that the percentage change in the surface tension was not the same in each case. The results of the measurements of surface tension are presented in the form of average values obtained during research.

Table 1. The surface tension for diferent types of water, with and without adjuvant

\begin{tabular}{|c|c|c|c|c|c|c|}
\hline & \multicolumn{4}{|c|}{ Surface tension $[\mathrm{mN} / \mathrm{m}]$} \\
\hline $\begin{array}{l}\text { Water } \\
\text { source* }\end{array}$ & $\begin{array}{l}\text { Recommended } \\
\text { dose of adjuvant }\end{array}$ & $\begin{array}{c}\text { Droplet } \\
\text { volume }[\mu \mathrm{l}]\end{array}$ & Average & MIN & MAX & $\begin{array}{l}\text { Standard } \\
\text { deviation }\end{array}$ \\
\hline \multirow{2}{*}{ A } & $0 \%$ & 28 & 71.79 & 70.88 & 72.96 & 0.52 \\
\hline & $100 \%$ & 14 & 44.17 & 42.30 & 46.76 & 1.17 \\
\hline \multirow{2}{*}{ B } & $0 \%$ & 28 & 71.56 & 70.34 & 72.39 & 0.53 \\
\hline & $100 \%$ & 14 & 36.26 & 34.16 & 38.45 & 1.23 \\
\hline \multirow{2}{*}{$\mathrm{C}$} & $0 \%$ & 28 & 73.41 & 71.60 & 75.04 & 0.66 \\
\hline & $100 \%$ & 14 & 36.87 & 33.43 & 40.24 & 1.96 \\
\hline \multirow{2}{*}{$\mathrm{D}$} & $0 \%$ & 28 & 73.83 & 72.43 & 75.01 & 0.58 \\
\hline & $100 \%$ & 14 & 48.88 & 42.03 & 54.50 & 3.33 \\
\hline
\end{tabular}

*A: demineralized water-UP Lublin; B: farm well-Sosnówka; C: tap water-UP Lublin; D: tap waterSosnówka.

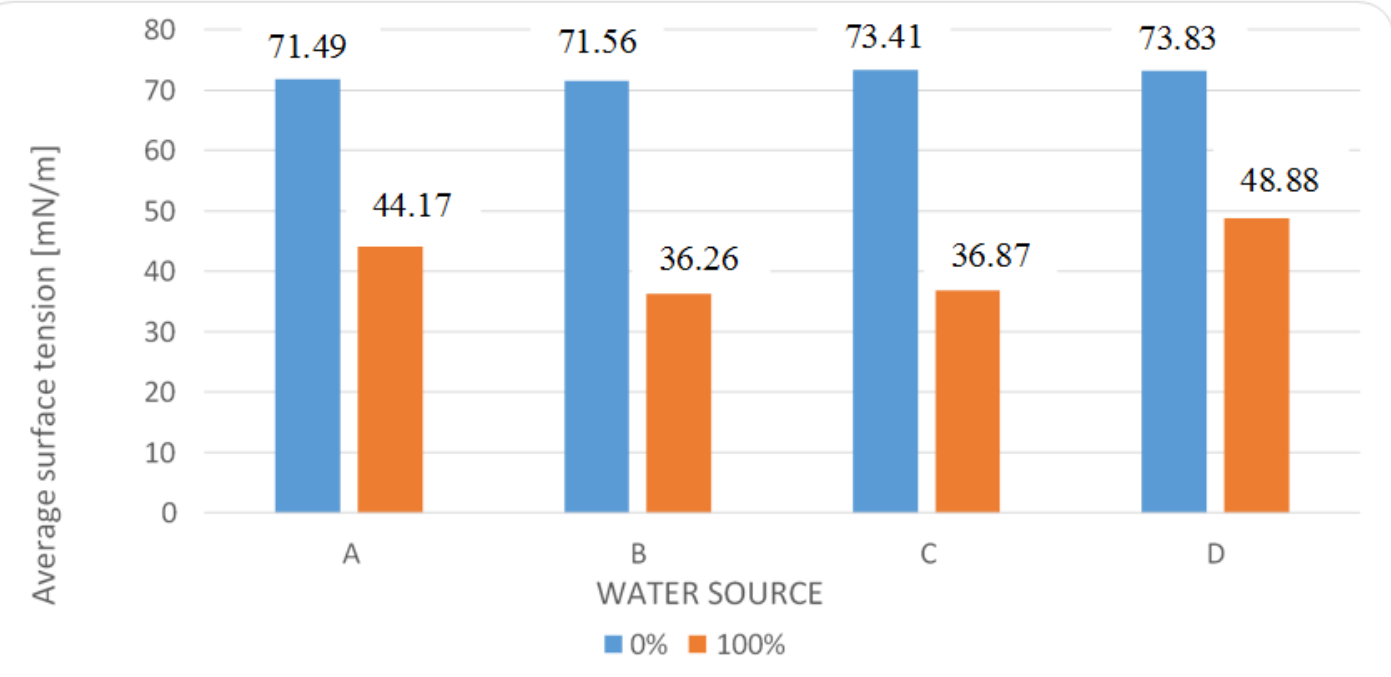

Figure 1. The average results of measurements of surface tension

*A: demineralized water-UP Lublin; B: farm well-Sosnówka; C: tap water-UP Lublin; D: tap waterSosnówka.

The average results (fig. 1) of the measurement of the surface tension of water without adjuvant were similar (ranged from 71 to 74). After the addition of the adjuvant. decrease in surface tension was observed. The largest decrease in surface tension after adding the recommended dose of the adjuvant was observed for the water from the source B and C. the decrease was almost half of the original value. Surface tension of water from the $\mathrm{A}$ and $\mathrm{D}$ are decreased by about $35 \%$ compared to the surface tension of water without the adjuvant.

The standard deviation of the water surface tension without the addition of adjuvant ranged from 0.52 to 0.66 (table 1). After using the adjuvant. the best value of the standard deviation gained from using water from source A and reached a value of 1.17. while the worst value (value 3.33 ) was when using water D. 
The obtained results show that the addition of adjuvant reduces the surface tension of water. and it is also reflected in the change in the droplet size produced by agricultural sprayers. The results of the measurements of volume median diameter are presented in the form of average values obtained during research.

Table 2. Mean values for the spray Volume median diameter (VMD). $\mu \mathrm{m}$

\begin{tabular}{|c|c|c|c|c|c|}
\hline \multirow{3}{*}{$\begin{array}{l}\text { Type } \\
\text { of } \\
\text { wate } \\
r\end{array}$} & \multirow{3}{*}{$\begin{array}{c}\text { Working } \\
\text { pressure } \\
\text {. bar }\end{array}$} & \multicolumn{4}{|c|}{ Dose of adjuvant } \\
\hline & & \multicolumn{2}{|c|}{$0 \%$} & \multicolumn{2}{|c|}{$100 \%$} \\
\hline & & $\begin{array}{l}\text { On the center of spray } \\
\text { pattern }\end{array}$ & $\begin{array}{l}\text { Average of all the } \\
\text { spray pattern }\end{array}$ & $\begin{array}{l}\text { On the center of } \\
\text { spray pattern }\end{array}$ & $\begin{array}{c}\text { Average of all } \\
\text { the spray } \\
\text { pattern }\end{array}$ \\
\hline \multirow{3}{*}{ A } & 2 & 205 & 252 & 196 & 240 \\
\hline & 3 & 179 & 216 & 175 & 209 \\
\hline & 4 & 171 & 198 & 168 & 192 \\
\hline \multirow{3}{*}{ B } & 2 & 212 & 234 & 193 & 228 \\
\hline & 3 & 176 & 212 & 178 & 203 \\
\hline & 4 & 168 & 190 & 164 & 187 \\
\hline \multirow{3}{*}{$\mathrm{C}$} & 2 & 208 & 238 & 196 & 234 \\
\hline & 3 & 187 & 212 & 184 & 204 \\
\hline & 4 & 179 & 198 & 168 & 190 \\
\hline \multirow{3}{*}{$\mathrm{D}$} & 2 & 202 & 238 & 195 & 234 \\
\hline & 3 & 182 & 210 & 177 & 206 \\
\hline & 4 & 169 & 189 & 164 & 188 \\
\hline
\end{tabular}

*A: demineralized water-UP Lublin; B: farm well-Sosnówka; C: tap water-UP Lublin; D: tap waterSosnówka.

Table 2 presents the results of VMD with and without adjuvant with different position. pressure and water source. The higher changes in the VMD were when using adjuvant (which mean the surface tension is smaller) with pressure 2 and 3 bar with all sources of water when averaging the results of all the spray pattern. When using 4 bar pressure there was difference in the VMD for the results obtained from the center position and the averaged result of the spray pattern. However. there was no difference for the same pressure when adding adjuvant or without it.

The figure 2 shows the drops size distribution for normal water (B) without adjuvant. There was difference in the drops size distribution for almost all the size ranges between the averaged results and the results which were obtained in the center of the spray pattern. These differences come from the diversity of the drop size distribution of the flat fan nozzle spray cloud. for this results the difference comes from the different drops size in the center of the spray pattern and the edges of this pattern.

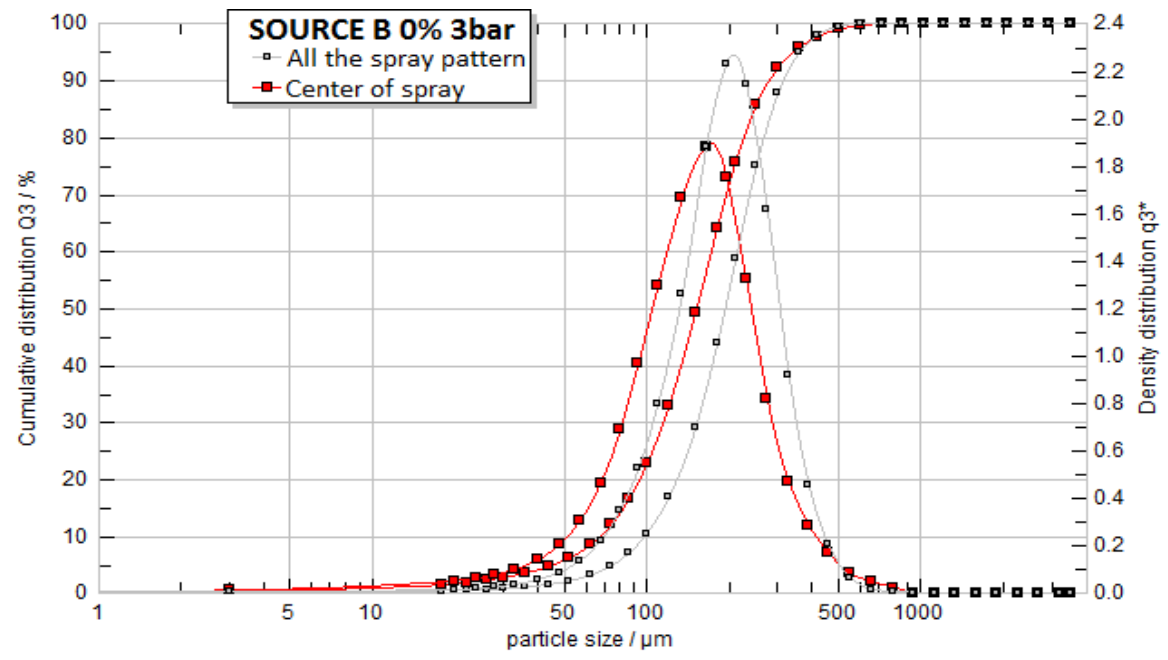

Figure 2. Distribution of droplet size produced by spray 
Table 3 shows drops size distribution with and without adjuvant in different measuring positions for the water from the source B. Adding the adjuvant did not result in a big difference in the drops size distribution for all the size ranges. However. from table 2. adding the adjuvant produced smaller values of VMD in the center position only with 2 bar pressure. For the averaged results. the VMD was smaller when using 2 and 3 bar pressure. This mean the VMD did not change with 3-bar pressure with and without adjuvant and in the center position. This explains why the drops size distribution was almost the same with and without adjuvant in the center position.

Table 3. Droplet size distribution for different dose of adjuvant

\begin{tabular}{|c|c|c|c|c|c|c|c|c|c|c|c|c|}
\hline & \multirow[b]{2}{*}{$\begin{array}{c}\text { Measurement } \\
\text { position }\end{array}$} & \multicolumn{11}{|c|}{ Droplet size distribution [\%] } \\
\hline & & $\begin{array}{c}0- \\
100\end{array}$ & $\begin{array}{r}100 \\
-150\end{array}$ & $\begin{array}{r}150 \\
-200\end{array}$ & $\begin{array}{r}200 \\
-250\end{array}$ & $\begin{array}{r}250 \\
-300\end{array}$ & $\begin{array}{r}300 \\
-350\end{array}$ & $\begin{array}{r}350 \\
-400\end{array}$ & $\begin{array}{r}400 \\
-450\end{array}$ & $\begin{array}{r}450 \\
-500\end{array}$ & $\begin{array}{l}500 \\
- \\
600 \\
\end{array}$ & $\begin{array}{l}600- \\
700\end{array}$ \\
\hline \multirow{2}{*}{$\begin{array}{c}\text { Water } \\
\text { source: B } \\
\text { dose of } \\
\text { adjuvant: } \\
0 \% \\
\text { Pressure: } \\
3 \text { bar }\end{array}$} & $\begin{array}{c}\text { Average of all } \\
\text { the spray } \\
\text { pattern }\end{array}$ & 10.82 & 18.57 & 23.94 & 20.51 & 12.75 & 6.25 & 3.39 & 1.70 & 1.05 & 0.67 & 0.21 \\
\hline & $\begin{array}{c}\text { On the center } \\
\text { of spray } \\
\text { pattern }\end{array}$ & 21.83 & 25.50 & 22.45 & 14.23 & 6.95 & 3.43 & 2.13 & 1.27 & 0.91 & 0.76 & 0.32 \\
\hline \multirow{2}{*}{$\begin{array}{c}\text { Water } \\
\text { source: B } \\
\text { dose of } \\
\text { adjuvant: } \\
100 \% \\
\text { Pressure: } \\
3 \text { bar }\end{array}$} & $\begin{array}{c}\text { Average of all } \\
\text { the spray } \\
\text { pattern }\end{array}$ & 10.10 & 19.48 & 24.83 & 20.51 & 12.32 & 6.08 & 3.41 & 1.74 & 1.07 & 0.44 & 0.02 \\
\hline & $\begin{array}{c}\text { On the center } \\
\text { of spray } \\
\text { pattern }\end{array}$ & 18.66 & 26.51 & 23.39 & 14.56 & 7.25 & 3.90 & 2.56 & 1.54 & 1.08 & 0.50 & 0.20 \\
\hline
\end{tabular}

\section{CONCLUSION}

The study has shown that:

1- The use of the recommended dose from the adjuvant manufacturer has significant impact on the change of the surface tension, but only slightly reduces the diversity of the produced droplets in the different areas of the spray cloud. Best use of adjuvant can be observed by changing the VMD for the whole spray cloud.

2- Spraying with 2-bar pressure results in bigger differences of the VMD with all water sources and in the different ways of calculating VMD.

3- Using different water sources results in different values of VMD in the center of the spray pattern and in the averaged VMD of the spray pattern.

4- The VMD in the center of the spray pattern does not represent the VMD of the whole spray cloud due to the diversity of the droplets size within the spray cloud.

\section{REFERENCES}

ASAE S572.1. (2009). Spray Nozzle Classification by Droplet Spectra. ASABE Standards. 4 pp.

Butler Ellis. M. C.; Tuck. C. R.; Miller. P. C. H.. (1997). The effect of some adjuvants on sprays produced by agricultural flat fan nozzles. Crop Protection. Guildford. v.16. n.1. p. 609-615.

Butler Ellis M C. Tuck C R. Miller P C H. (2001). How surface tension of surfactant solutions influences the characteristics of sprays produced by hydraulic nozzles for pesticide application. Colloids and Surfaces A: Physiochemical and Engineering Aspects 180: 267-276.

Czaczyk Z. (2014). Drop-size classification according to requirements of pesticides labels. Progress In Plant Protection 54 (1).

Directive 2009/128/EC of the European Parliament and of the Council of 21 October 2009 establishing a framework for Community action to achieve the sustainable use of pesticides. Official Journal of the European Union. L. 309/71. 24 November (2009). 
Huyghebaert B. (2015). Verification of measurement methods of flat fan nozzles working parameters used in agriculture. $\mathrm{PhD}$ Thesis. University of Life Sciences in Lublin. Poland.

Massinon. M.. De Cock. N.. Forster. W. A.. Nairn. J. J.. McCue. S. W.. Zabkiewicz. J. A.. \& Lebeau. F. (2017). Spray droplet impaction outcomes for different plant species and spray formulations. Crop Protection. 99. 65-75.

Subr. A. K.. Sawa. J.. \& Parafiniuk. S. (2015). Practical Deviation in Sustainable Pesticide Application Process. Agriculture and Agricultural Science Procedia. 7. 241-248. http://doi.org/10.1016 /j.aaspro.2015.12.037.

User Manual V1.92-03 Software for Drop Shape Analysis DSA1 v 1.92 for contact angle measurements systems (2004). KRÜSS GmbH. Hamburg. 